\title{
Clinical features and treatment outcome of non-small cell lung cancer (NSCLC) patients with uncommon or complex epidermal growth factor receptor (EGFR) mutations
}

\author{
Stefano Frega ${ }^{1,6, *}$, Martina Lorenzi ${ }^{1, *}$, Matteo Fassan ${ }^{2}$, Stefano Indraccolo ${ }^{3}$, Fiorella \\ Calabrese $^{4}$, Adolfo Favaretto5 , Laura Bonanno ${ }^{6}$, Valentina Polo ${ }^{1,6}$, Giulia Zago ${ }^{6}$, \\ Francesca Lunardi ${ }^{4}$, Ilaria Attilii,6, Alberto Pavan ${ }^{1,6}$, Massimo Rugge ${ }^{2}$, Valentina \\ Guarneri $^{1,6}$, PierFranco Conte ${ }^{1,6}$, Giulia Pasello ${ }^{6}$ \\ ${ }^{1}$ Department of Surgical, Oncological and Gastroenterological Sciences, University of Padova, Padova, Italy \\ ${ }^{2}$ Department of Medicine, Surgical Pathology Unit, University of Padova, Padova, Italy \\ ${ }^{3}$ Immunology and Molecular Oncology Unit, Istituto Oncologico Veneto IRCCS, Padova, Italy \\ ${ }^{4}$ Department of Cardio-Thoracic and Vascular Sciences, University of Padova, Padova, Italy \\ ${ }^{5}$ Medical Oncology, Azienda ULSS 9, Treviso, Italy \\ ${ }^{6}$ Medical Oncology 2, Istituto Oncologico Veneto, IRCCS, Padova, Italy \\ *These authors contributed equally to this work
}

Correspondence to: Giulia Pasello, email: giulia.pasello@ioveneto.it

Keywords: lung cancer, non-small cell, epidermal growth factor receptor, mutations, tyrosine kinase inhibitors

Received: October 28, $2016 \quad$ Accepted: February 22, $2017 \quad$ Published: March 06, 2017

Copyright: Frega et al. This is an open-access article distributed under the terms of the Creative Commons Attribution License (CC-BY), which permits unrestricted use, distribution, and reproduction in any medium, provided the original author and source are credited.

\section{ABSTRACT}

Introduction: Tyrosine-kinase inhibitors (TKIs) represent the best treatment for advanced non-small cell lung cancer (NSCLC) with common exon 19 deletion or exon 21 epidermal growth factor receptor mutation (EGFRm). This is an observational study investigating epidemiology, clinical features and treatment outcome of NSCLC cases harbouring rare/complex EGFRm.

Results: Among 764 non-squamous NSCLC cases with known EGFRm status, 26(3.4\%) harboured rare/complex EGFRm. Patients receiving first-line TKIs $(N=17)$ achieved median Progression Free Survival (PFS) and Overall Survival (OS) of 53 (IC 95\%, 2-105) and 84 (CI 95\%, 27-141) weeks respectively, without significant covariate impact. Response Rate and Disease Control Rate (DCR) were $47 \%$ and $65 \%$, respectively. Uncommon exon 19 mutations achieved longer OS and PFS and higher DCR compared with exon 18 and 20 mutations. No additional gene mutation was discovered by MassARRAY analysis. TKIs were globally well tolerated.

Materials and methods: A retrospective review of advanced non-squamous NSCLC harbouring rare/complex EGFRm referred to our Center between 2010 and 2015 was performed. Additional molecular pathways disregulation was explored in selected cases, through MassARRAY analysis.

Conclusions: Peculiar clinical features and lower TKIs sensitivity of uncommon/ complex compared with common EGFRm were shown. Exon 19 EGFRm achieved the best TKIs treatment outcome, while the optimal treatment of exon 18 and 20 mutations should be further clarified.

\section{INTRODUCTION}

The clinical knowledge of Epidermal Growth Factor Receptor (EGFR) molecular status and its therapeutic application, emerging in the early 2000s [1], has revolutionized non-small cell lung cancer (NSCLC) management, paving the way for targeted therapies. EGFR mutations (EGFRm) are typical of about $15 \%$ of NSCLC, mostly with adenocarcinoma histology, and quite peculiar of no smoker or former smoker patients [2]. 
Most EGFRm are strong predictors of response to tyrosine-kinase inhibitors (TKIs), with particular reference to the commonest E746-A750 deletion on exon 19 (ELREA) and L858R mutation in exon 21 [3].

Randomized phase III trials showed progression free survival (PFS) and response rate (RR) benefit of EGFR TKIs compared to platinum-doublets chemotherapy as first line treatment of EGFR mutated NSCLC [4-7], with subsequent post-hoc or preplanned subgroup analyses revealing higher benefit in cases harbouring classical exon 19 deletion [5-10].

Uncommon or rare EGFRm are all exons 18-21 alterations with the exception of common sensitizing cited above, or all those with a prevalence lower than 5\% [11]. These gene alterations are in continuous discovery with variable frequency and sensitivity to targeted therapy [12].

Complex mutations are characterized by two or more different EGFRm in the same tumor sample, with heterogeneous prevalence reported [13-17]

The hypothetical carcinogenesis pattern of this special subset of EGFR-driven lung cancer, based on few in vivo and in vitro data, can be summarized in the principle "the unit is strength": when a mutation with a low-intermediate oncogenic potential is not able itself to give rise to cancer, an additional one is required [13].

So far, no clinical trial has been designed to identify the best treatment for patients with these EGFR molecular variants, and maybe their relatively low incidence could constitute an obstacle to conceive it. Only post-hoc analyses of clinical trials, retrospective studies, case reports and in vitro findings addressed this issue, suggesting that uncommon EGFRm respond less to TKIs [12].

In a subgroup analysis of the NEJ002 study, the small number of patients with G719X or L861Q mutations $(N=5)$ treated with gefitinib showed shorter OS compared to those with common mutations[18]; data from a nationwide survey showed some activity of first generation TKIs gefitinib and erlotinib in patients with G719X-L861Q-S768I mutations, however with lower RR, PFS and overall survival (OS) compared with classical EGFR mutations [19].

A post-hoc analysis of combined LUX-Lung trials showed that afatinib achieves a median PFS of 10.7 months in patients with at least one of the three above mentioned uncommon mutations [20], not much lower than PFS seen in common mutations. We should consider that this patients group $(N=38)$ was heterogeneous, with almost half of them carrying a double mutation. An indirect proof of the apparent greater power of second generation TKIs in some uncommon EGFRm is their lower growth inhibitory concentration for in vitro growth arrest of cells transfected with exon 18 EGFR gene mutations [21].

If mutations discussed so far can be catalogued as partially sensitive, exon 20 mutations cluster encloses different types of modifications, [22, 23] including T790M with recognized resistance and low RR to first and second TKIs generation.

A wide subset of exon 20 insertions, whose mechanism of primary resistance are poorly understood, accounts as the third commonest de novo EGFR mutation: no shared consensus exists for treatment of such cases, for which chemotherapy regimens could represent a valid option. On the other hand, specifically designed third generation TKIs have been already proved to work against de novo or acquired T790M mutation, where resistance is principally due to increase in receptor affinity for adenosine triphoshate (ATP) [24]

Clinical reports about all other single pointmutations, in-frame deletions, in-frame duplications or insertions are anecdotal, as are those about patients with NSCLC harbouring complex EGFRm, representing the $6 \%$ of all EGFR mutated lung adenocarcinoma in a described Asian population [14].

The limited available data don't allow us to draw any conclusions about the optimal treatment of this special class of patients.

The aim of our observational retrospective study was to describe epidemiology, clinical features and treatment outcome of uncommon and/or complex EGFRm in a case series of NSCLC patients referring to our Institute. We also explored the coexistence of additional mutations in different genes in a patient subgroup having rare/complex EGFRm.

\section{RESULTS}

\section{Epidemiology and clinical features of rare and complex mutations}

Between 2010 and 2015, 992 patients with nonsquamous NSCLC diagnosis referred to our Institute. EGFR mutational status was assessed in 764 patients; among these, no gene alteration was found in 675 (88\%) cases, while $89(12 \%)$ subjects resulted EGFR mutated; assessment of mutational status was not performed in 228 cases which were excluded from the study.

Uncommon and complex EGFRm accounted for $3.4 \%$ of all non-squamous NSCLC cases. Among patients with EGFRm $(N=89), 63(71 \%)$ presented a common mutation (ELREA or L858R), 24 (27\%) a rare isolated mutation and $2(2 \%)$ a complex mutation made of at least two rare mutations (Figure 1). Analyzing clinical features, median age was 68 year old (range, 47-86), with slight majority of females $(N=14,54 \%)$. Sixteen (62\%) patients received adenocarcinoma diagnosis, with histological subtypes mucinous/enteric in $6(23 \%)$, acinar in $4(15 \%)$, papillary in $2(8 \%)$, poorly differentiated in 3 $(12 \%)$, and lepidic in $1(4 \%)$ cases; not otherwise specified (NOS) non squamous lung cancer was diagnosed in 10 $(38 \%)$ cases. Smoking history was negative in half of the sample, while 12 patients $(46 \%)$ have been exposed to 
smoke, equally divided in still smoker and former-smoker at diagnosis time; in an isolated case (4\%) smoking status was unknown. At the diagnosis time, almost all patients presented in an optimal or good Eastern Cooperative Oncology Group (ECOG) performance status (PS), with $6(23 \%)$ and $19(73 \%)$ of them having 0 and 1 score respectively, despite the majority of them $(N=17,65 \%)$ having stage IV. Advanced/metastatic stage was present in 24 patients at the diagnosis $(N=18,70 \%)$ or subsequently to disease relapse $(N=6,23 \%)$; metastatic spread were mostly in one $(N=10,38 \%)$ or two $(N=9,35 \%)$ sites.

Most patients $(N=15,58 \%)$ received only one systemic treatment line, while $8(31 \%)$ patients received two or more treatment lines. Among the three patients $(12 \%)$ not receiving any systemic treatment, two had an early stage disease and one had a relapse site suitable of loco-regional treatment (Table 1). No case of combined common mutations was observed. Among uncommon mutations, we observed a numerically homogeneous distribution in exon 18, 19 and 20 while no case of rare isolated mutation in exon 21 was found (Table 2).

\section{Treatment outcome}

All patients with advanced/metastatic disease $(N=23,95 \%)$ received a systemic treatment. First or second generation TKIs were prescribed in $17(71 \%)$ patients: gefitinib in $11(46 \%)$, erlotinib in $3(12.5 \%)$ and afatinib in $3(12.5 \%)$ cases. A platinum-based chemotherapy with or without an anti-angiogenic drug was administered to $5(21 \%)$ patients; one $(4 \%)$ patient was treated with an anti-programmed cell death protein 1 (PD-1) monoclonal antibody in the context of a randomized clinical trial (Figure 1).

In the group of patients receiving a systemic treatment for advanced/metastatic disease, we observed $8(35 \%)$ cases of partial response(PR) and $8(35 \%)$ cases of stable disease(SD), $7(30 \%)$ cases of progressive disease(PD) and no case of complete response(CR). RR was 35\% (95\% confidence interval CI; 16\%-57\%), while disease control rate(DCR) was 70\% (95\% CI; 47\%-87\%). All patients harboring a resistance exon 20 EGFR mutation, who received first-line chemotherapy, achieved a stable disease.

Among patients who received an EGFR TKI $(N=17)$ we observed $8(47 \%)$ PR, $3(18 \%)$ SD and 6 (35\%) PD; RR was 47\% (95\% CI; 23\%-72\%) with DCR of $65 \%(95 \%$ CI; 38\%-86\%) (Table 3).

With a median follow-up of 38 weeks, median PFS and OS in patients treated with first-line EGFR TKIs were 53 weeks (CI 95\%, 2-105) and 84 weeks (CI 95\%, 27-141) respectively (Figure 2).

Longer PFS and OS were shown in patients treated with first-line EGFR TKIs compared with chemotherapy, even though without statistical significance, likely because of the small sample size (Supplementary Figure 1).

We observed an isolated PR (25\%) in the subgroup 1, and $3(75 \%)$ cases of PD at the first radiological assessment;

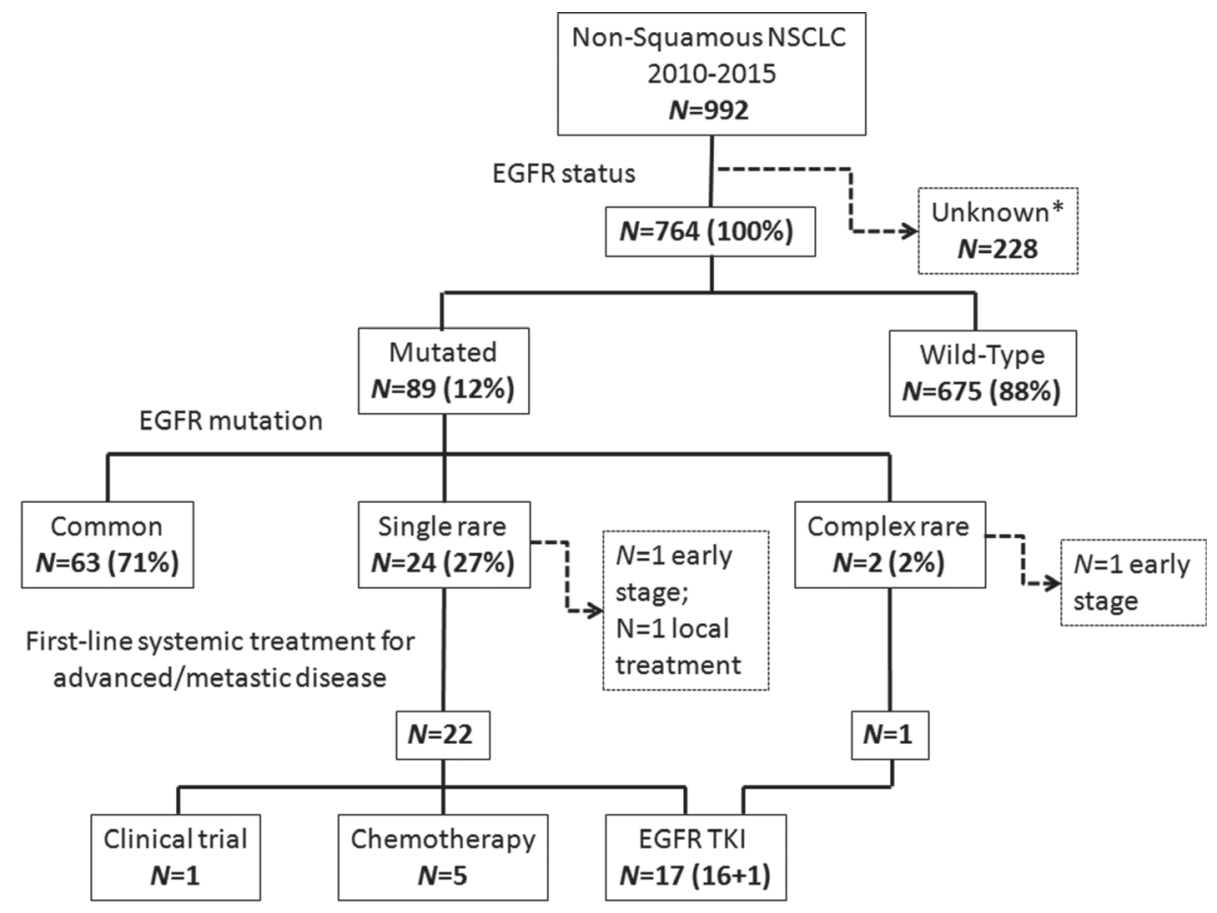

*EGFR status assessment not performed

Figure 1: Consort diagram of the study population. NSCLC: Non-Small Cell Lung Cancer; EGFR: Epidermal Growth Factor Receptor; TKI: Tyrosine Kinase Inhibitors. 
Table 1: Main clinical and pathologic characteristics of 24 patients with rare/complex EGFR m

\begin{tabular}{|c|c|}
\hline Clinical feature & $N=26(100 \%)$ \\
\hline $\begin{array}{l}\text { Gender } \\
\text { Male } \\
\text { Female }\end{array}$ & $\begin{array}{l}12(46 \%) \\
14(54 \%)\end{array}$ \\
\hline $\begin{array}{l}\text { Age } \\
\quad \text { Median (range) }\end{array}$ & $68(47-86)$ \\
\hline $\begin{array}{l}\text { ECOG score } \\
0 \\
1 \\
2 \\
3 \\
\end{array}$ & $\begin{array}{c}6(23 \%) \\
19(73 \%) \\
0(0 \%) \\
1(4 \%)\end{array}$ \\
\hline $\begin{array}{l}\text { Smoking status } \\
\quad \text { Current Smoker } \\
\text { Former smoker } \\
\text { Non smoker } \\
\text { Unknown } \\
\end{array}$ & $\begin{array}{c}6(23 \%) \\
6(23 \%) \\
13(50 \%) \\
1(4 \%) \\
\end{array}$ \\
\hline $\begin{array}{l}\text { Histology } \\
\text { Lepidic } \\
\text { Acinar } \\
\text { Papillary } \\
\text { Mucinous } \\
\text { Enteric } \\
\text { Poorly differentiated } \\
\text { Not otherwise specified (NOS) }\end{array}$ & $\begin{array}{c}1(4 \%) \\
4(15 \%) \\
2(8 \%) \\
4(15 \%) \\
2(8 \%) \\
3(12 \%) \\
10(38 \%)\end{array}$ \\
\hline $\begin{array}{l}\text { Stage at diagnosis } \\
\text { Stage I } \\
\text { Stage II } \\
\text { Stage III } \\
\text { Stage IV } \\
\end{array}$ & $\begin{array}{c}4(15 \%) \\
3(12 \%) \\
2(8 \%) \\
17(65 \%) \\
\end{array}$ \\
\hline $\begin{array}{l}\text { Surgery } \\
\text { Radical } \\
\text { Radical and palliative } \\
\text { Palliative } \\
\text { Palliative } \\
\text { Diagnostic } \\
\text { None }\end{array}$ & $\begin{array}{c}7(27 \%) \\
1(4 \%) \\
2(8 \%) \\
2(8 \%) \\
14(54 \%)\end{array}$ \\
\hline $\begin{array}{l}\text { Neoadjuvant/adjuvant therapy } \\
\text { Yes } \\
\text { No }\end{array}$ & $\begin{array}{r}5(19 \%) \\
21(81 \%)\end{array}$ \\
\hline $\begin{array}{l}\text { Advanced disease } \\
\text { Yes, at diagnosis } \\
\text { Yes, at recurrence } \\
\text { No }\end{array}$ & $\begin{array}{r}18(69 \%) \\
6(23 \%) \\
2(8 \%)\end{array}$ \\
\hline $\begin{array}{l}\text { Metastatic sites } \\
\quad 0 \\
1 \\
2 \\
3 \\
4\end{array}$ & $\begin{array}{r}3(12 \%) \\
10(38 \%) \\
9(35 \%) \\
3(12 \%) \\
1(4 \%)\end{array}$ \\
\hline
\end{tabular}




\begin{tabular}{|l|c|}
\hline Treatment lines & \\
One & $15(58 \%)$ \\
Two & $6(23 \%)$ \\
Three & $2(8 \%)$ \\
None & $3(12 \%)$ \\
\hline Radiotherapy & \\
Palliative & $4(15 \%)$ \\
Adjuvant & $1(4 \%)$ \\
None & $21(81 \%)$ \\
\hline
\end{tabular}

Table 2: Rare and complex genetic alterations in EGFR gene kinase domain

\begin{tabular}{|c|c|c|c|c|}
\hline Exon & Mutation type & Aminoacid change & $\mathbf{N}$ & $\begin{array}{c}\text { \% of total } \\
\text { mutated }\end{array}$ \\
\hline \multirow[t]{2}{*}{ Exon 18} & \multirow[t]{2}{*}{ Point mutations } & E709K/Q/Stop & 3 & $3 \%$ \\
\hline & & G719A/C/S & 4 & $4 \%$ \\
\hline \multirow[t]{8}{*}{ Exon 19} & \multirow[t]{2}{*}{ Insertions } & I745insKIPVAI & 1 & $1 \%$ \\
\hline & & L747-S752; insP & 1 & $1 \%$ \\
\hline & \multirow[t]{4}{*}{ Insertions/ Deletions } & del747-K754insSR & 1 & $1 \%$ \\
\hline & & del L747-P753insQ & 1 & $1 \%$ \\
\hline & & delE746-S752insV & 1 & $1 \%$ \\
\hline & & delL747-P753insS & 2 & $2 \%$ \\
\hline & \multirow[t]{2}{*}{ Deletions } & L747-K754 & 1 & $1 \%$ \\
\hline & & S752-I759 & 1 & $1 \%$ \\
\hline \multirow[t]{8}{*}{ Exon 20} & \multirow[t]{3}{*}{ Insertions } & H773 ins HPH & 1 & $1 \%$ \\
\hline & & V769insASV & 1 & $1 \%$ \\
\hline & & D770insSVD & 1 & $1 \%$ \\
\hline & Duplications & Asn771_His773dup & 1 & $1 \%$ \\
\hline & \multirow{3}{*}{ Point mutations } & S768R & 1 & $1 \%$ \\
\hline & & H773G & 1 & $1 \%$ \\
\hline & & Q812R & 1 & $1 \%$ \\
\hline & Not specified & - & 1 & $1 \%$ \\
\hline $\begin{array}{l}\text { Exons } 18 \\
\text { plus } 21\end{array}$ & Combined point mutations & $\begin{array}{l}\text { E709K } \\
\text { L833V } \\
\text { H835L }\end{array}$ & 1 & $1 \%$ \\
\hline $\begin{array}{l}\text { Exons } 18 \\
\text { plus } 20\end{array}$ & Combined point mutations & $\begin{array}{l}\text { G719A } \\
\text { V769M }\end{array}$ & 1 & $1 \%$ \\
\hline
\end{tabular}

$6(67 \%)$ patients reported PR and $3(33 \%)$ a SD in the subgroup 2; all three patients within the subgroup 3 had PD. No significant differences in terms of RR were observed between subgroups, while higher DCR was shown in subgroup 2 compared with subgroup $1(p=0.014)$ and $3(p=0.0045)$ (See Supplementary Figure 2$)$. The only patient harbouring a complex mutation 3 (subgroup 4) showed a partial response to TKIs.

PFS was significantly longer in subgroup 2 (median PFS: not reached) compared with subgroup 1 (median PFS 8 weeks, $p=0.037$, CI 95\%) and subgroup 3 (median PFS 17 weeks, $p=0.0009$, IC 95\%) (Figure 3A).
Rare mutations on exon 19 were also predictive of longer survival (median OS: not reached) compared with rare mutations in exon 18 (mwedian OS 8 weeks, $p=0.014$, CI 95\%) or exon 20 (median OS 17 weeks, $p=0.014$, CI 95\%) (Figure 3B)

Median PFS and OS were not reached in the subgroup 4.

No covariate significantly impacts on PFS and OS at the univariate (See Supplementary Table 1) and multivariate (See Supplementary Table 1) analyses, even though data should be interpreted with caution, due to the limited sample size. 


\section{Treatment tolerability}

An adverse event (AE) of any grade was observed in $13(76 \%)$ patients. Maximum grade $(\mathrm{G})$ of $\mathrm{AE}$ was 1 in $5(33 \%)$ patients, G2 in $6(35 \%)$ patients, and G3 in $1(6 \%)$ patient receiving gefitinib.

Temporary treatment interruption for any cause was registered in $5(29 \%)$ patients, while interruptions due to drug-related AE were $2(11 \%)$, both in patients receiving afatinib. No case of permanent treatment discontinuation was observed.

Dose reduction was required only in one patient (5\%) taking afatinib. More frequently observed $\mathrm{AE}$ were diarrhea $(N=8,47 \%)$, paronychia $(N=7,41 \%)$, asthenia $(N=4,24 \%)$, mucositis $(N=2,12 \%)$ with isolated cases of skin dryness, corneal erosion, urinary tract infection and nausea (See Supplementary Table 3).

The incidence of any drug-related $\mathrm{AE}$ was higher for afatinib $(N=3,100 \%)$, than for gefitinib or erlotinib $(N=8,73 \%$ and $N=2,67 \%$ respectively). No statistically significant difference in terms of AE between patients receiving erlotinib compared to those treated with two other TKIs $(p=1.00)$, and between first and second generation TKIs $(p=1.00)$ were observed.

\section{Exploratory analysis of additional molecular alterations in genes other than EGFR}

We searched for additional molecular alterations in other genes as possible driver of tumor progression, in the subgroup of cases $(N=6)$ with complex EGFRm or with rare EGFR mutations not responsive to first-line EGFR TKIs. Analyzed genes by multiplex PCR sequencing (Sequenom) included kras, braf, nras, pi3kca, alk, erbb2,

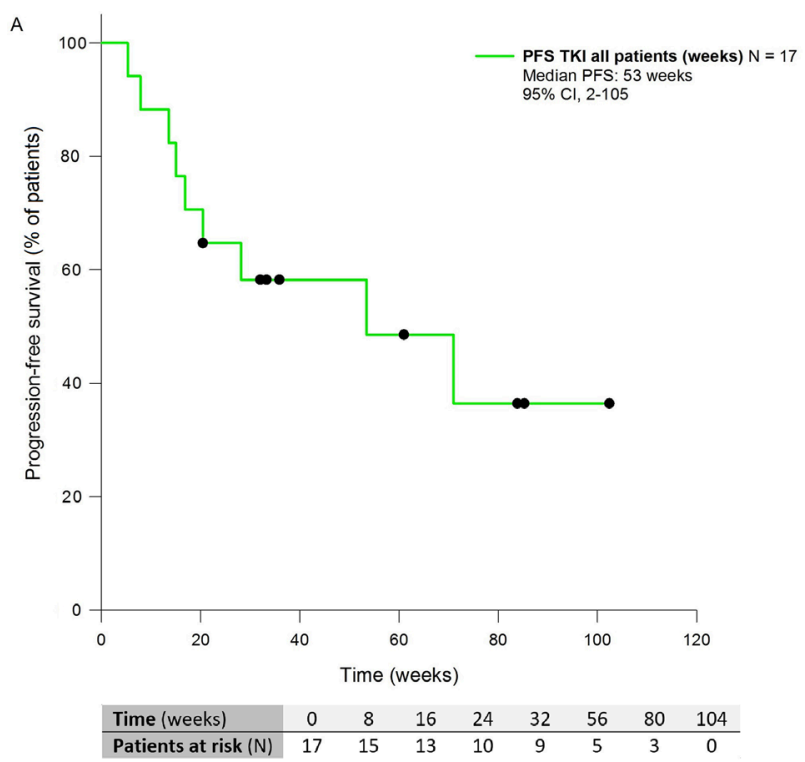

ddr2, mapk1 and ret. MassARRAY analysis confirmed EGFR mutations but did not disclose additional mutations.

\section{DISCUSSION}

Looking at results of available phase III clinical trials, EGFRm in NSCLC represent a strong predictive factor to EGFR TKIs. However, most studies consider only more frequent EGFRm, namely the deletion (ELREA) in exon 19 and the point mutation L858R in exon 21. On the contrary, there are no clear data about epidemiology, clinical features and drugs efficacy in patients harboring uncommon mutations. Survival results in patients with uncommon gene alterations, extrapolated from few randomized clinical trials comparing targeted therapies versus chemotherapy (IPASS, NEJGSG002, LUX-LUNG 3 e LUX-LUNG 6), $[8,18,20]$ provide some information but the small sample size and the heterogeneous clinical impact of such mutations limit their application in the 'reallife' practice. These critical issues were the basis for the design of this retrospective study on a series of patients referred to our Center. The descriptive purpose of the study offers some useful evidence about patient management based on clinical practice, especially considering how difficult could be to realize prospective studies restricted to subjects with rare and/or complex mutations. In our study, $12 \%$ of lung adenocarcinomas carried an EGFR mutation, a prevalence in line with literature data in Caucasian populations.[2, 28].

Uncommon and complex mutations accounted for less than $4 \%$ of all non-squamous NSCLC cases. Among cases carrying EGFRm, 71\% had a common mutation and $27 \%$ a rare mutation, while $2 \%$ a complex mutation.

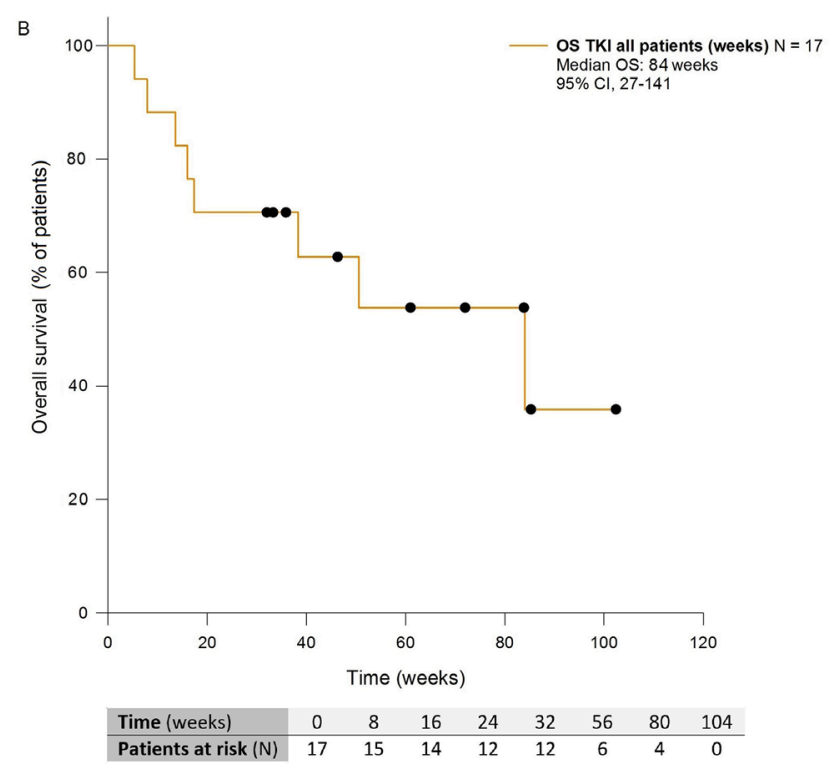

Figure 2: Kaplan-Meier curves showing PFS (A) and OS (B) of patients with NSCLC harboring rare and complex EGFR mutations and receiving EGFR TKIs front-line. PFS: Progression-free Survival; OS: Overall Survival; TKI: Tyrosine kinase Inhibitors; CI: Confidence Interval. 
Table 3: Clinical features and best radiological response to treatment of each patient harbouring rare and/or complex mutations

\begin{tabular}{|c|c|c|c|c|c|c|}
\hline Sex & $\begin{array}{c}\text { Age } \\
\text { (years) }\end{array}$ & $\begin{array}{c}\text { Smoking } \\
\text { status }\end{array}$ & Histology & Mutation & $\begin{array}{c}1^{\circ} \text { line } \\
\text { therapy }\end{array}$ & $\begin{array}{c}\text { Best } \\
\text { response }\end{array}$ \\
\hline M & 71 & Former & NOS & $\begin{array}{l}\text { ex } 18 \mathrm{E} 709 \mathrm{~K} \\
\text { ex } 21 \mathrm{~L} 833 \mathrm{~V} / \mathrm{H} 835 \mathrm{~L}\end{array}$ & afatinib & PR \\
\hline $\mathrm{F}$ & 69 & Current & Acinar & $\begin{array}{l}\text { ex } 18 \text { G719A } \\
\text { ex } 20 \mathrm{~V} 769 \mathrm{M}\end{array}$ & - & - \\
\hline M & 56 & No & Mucinous & ex 19 I745insKIPVAI & erlotinib & SD \\
\hline $\mathrm{F}$ & 68 & Former & NOS & ex $20 \mathrm{Q} 812 \mathrm{R}$ & $\mathrm{CT}$ & PD \\
\hline $\mathrm{F}$ & 68 & Former & Acinar & ex 20 D770insSVD & - & - \\
\hline M & 62 & No & NOS & ex 20 (His773G) & $\mathrm{CT}$ & SD \\
\hline M & 54 & Former & Papillary & ex 20 (unspecified) & CT & SD \\
\hline $\mathrm{F}$ & 56 & No & Mucinous & ex 20 Asn771_His773dup & erlotinib & PD \\
\hline $\mathrm{F}$ & 66 & Current & Poorly diff. & ex 20 H773 ins HPH & erlotinib & PD \\
\hline M & 73 & Current & Poorly diff. & ex 18 E709K & gefitinib & PD \\
\hline M & 86 & No & NOS & ex 18 E709Stop & gefitinib & PD \\
\hline $\mathrm{F}$ & 71 & Unknown & Mucinous & ex 19 del747-K754insSR & gefitinib & SD \\
\hline $\mathrm{F}$ & 79 & No & Mucinous & ex $20 \mathrm{~S} 768 \mathrm{R}$ & gefitinib & PD \\
\hline $\mathrm{F}$ & 56 & Current & Mucinous & ex 19 del L747-P753insQ & gefitinib & $\mathrm{SD}$ \\
\hline M & 68 & No & Lepidic & ex 18 E709Q & - & - \\
\hline $\mathrm{M}$ & 51 & No & Acinar & ex 19 delE746-S752insV & gefitinib & $\mathrm{PR}$ \\
\hline $\mathrm{F}$ & 74 & No & Poorly diff. & ex 19 delL 747-K754 & afatinib & PR \\
\hline $\mathrm{M}$ & 53 & No & Mucinous & ex 18 G719A & $\mathrm{CT}$ & SD \\
\hline $\mathrm{F}$ & 64 & Unknown & NOS & ex 20 V769insASV & $\mathrm{CT}$ & SD \\
\hline $\mathrm{F}$ & 76 & No & Papillary & ex 19 del S752-I759 & gefitinib & PR \\
\hline $\mathrm{M}$ & 60 & Former & Acinar & ex 18 G719C & gefitinib & PR \\
\hline $\mathrm{F}$ & 73 & No & NOS & ex 19 L747-S752;insP & gefitinib & PR \\
\hline M & 79 & Former & NOS & $\begin{array}{l}\text { ex } 182155 \mathrm{G}>\mathrm{A}, \\
\text { pGly719Ser }\end{array}$ & gefitinib & PD \\
\hline $\mathrm{F}$ & 75 & No & NOS & ex 19 delL747-P753insS & gefitinib & PR \\
\hline M & 54 & Current & NOS & ex 19 delL747-P753insS & afatinib & PR \\
\hline $\mathrm{F}$ & 47 & Current & NOS & ex 18 G719A & $\mathrm{CT}$ & SD \\
\hline
\end{tabular}

M: Male; F: Female; Diff: differentiated; NOS: not otherwise specified; ex: exon; CT: chemotherapy; PR: partial response; $\mathrm{SD}$ : stable disease; PD: progressive disease

The percentage of rare mutations is slightly higher than in other studies; $[15,18]$ similar frequencies were only identified in an Australian study, in which the incidence was about $25 \%$ of a small sample size. [29] Instead it's not yet completely elucidated the incidence of complex mutations, ranging from 3 to $25 \%$, [13, 15-17] as well as their most plausible role in malignancies development: the appealing sequential selection of suboptimal mutation model, for example, doesn't clarify the meaning of an additional mutation combined to a common one [30].

We reported a prevalence of G719X and E709X point mutations in exon 18 (7\%) and insertions/ duplications in exon $20(4 \%)$ in line with previous studies
$[21,28,31,32]$ while the prevalence of exon 19 insertions $(5 \%)$ were quite higher than that reported in the literature data [33]. No rare mutation in exon 21 alone was observed; on the contrary two synchronous exon 21 point mutations (L883V/H835L) have been found in a subject with triple complex mutation [34], a previously detected finding by other groups [35].

With regard to the clinical characteristics of studied subjects, we observed a considerable incidence of acinar and mucinous/enteric subtypes (15\% and 23\% respectively), in contrast with literature data reporting no EGFRm in mucinous subtype.[36, 37] This is an interesting finding considering the increasing incidence 
of such histologic subtype, probably because of the implementation of the lung adenocarcinoma diagnostic and classification process, and the lack of data on the optimal treatment of this kind of aggressive neoplasia poorly responsive to standard chemotherapy. The percentage of patients currently exposed to cigarette smoke in our series $(23 \%)$ is superior than reported for common sensitizing mutation (about 6\%), while the percentage of current and previous smokers (46\%) is only slightly higher. [38] This finding was reported in two other European studies: Lohinai et al. showed a statistically significant association between rare EGFRm and smoking habits [39], while Pallis et al. showed that the percentage of smokers is higher, although not significantly, in uncommon EGFRm than in classical one. [40] Furthermore, Beau-Faller et al. reported a higher frequency of exon 18 mutations in smokers [28]; in our study, patients with exon 18 mutations (rare or complex) showed smoking exposure in six of nine cases $(67 \%)$. The response rate (RR) of patients with rare and complex mutations treated with TKIs was $47 \%(95 \% \mathrm{CI} ; 23 \%-72 \%)$, while the rate of disease control (DCR) was 65\% (95\% CI; 38\%-86\%). Similar findings have already been reported in other studies [41] in which RR to TKIs varies between $34 \%$ and $50 \%$ and the DCR between $57.4 \%$ and $75.6 \%$, in any case lower than those of common mutations for which RR is greater than $60 \%$ for both first and second generation drugs.

However, with the obvious limits of an indirect comparison, survival parameters of our patients with rare EGFRm seemed more encouraging than those of patients with similar molecular characteristics,

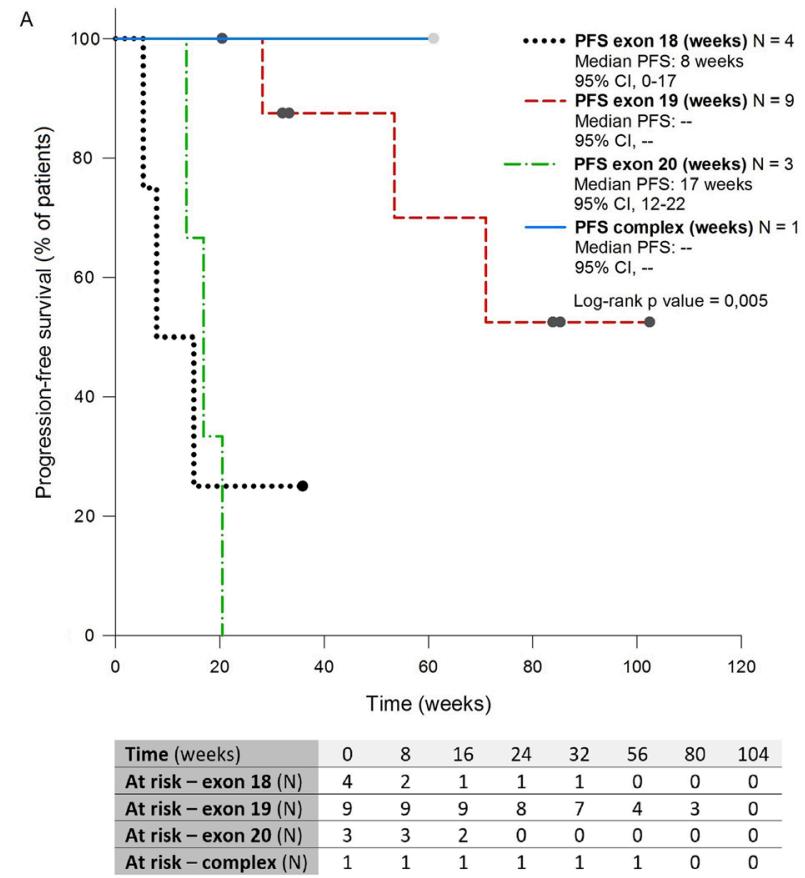

previously published [42]. In particular, median PFS and OS in TKI treated sample were of 13 and 20 months, respectively. These values didn't reach anyway outcome data reported in the first-line pivotal trials $[5,8]$ comparing TKIs versus chemotherapy in patients harboring common EGFR alterations. Moreover, real-life data from a subset of mutated patients referred to our Institute showed a median PFS in uncommon mutations group not significantly lower than in common mutation group, where median PFS was 14 months (15 months and 9 months in patients harboring exon 19 deletions and exon 21 mutations, respectively) (Supplementary Figure 3). On the same way, DCR in our case series harbouring common mutations was $90 \%$ (57\% PR and $33 \%$ of SD), not significantly higher than DCR in subgroup 2 (data not shown).

The heterogeneous prevalence of different uncommon mutations might explain such controversial results, as much as the retrospective nature of most case series.

We also analyzed the predictive role of different uncommon mutations by dividing patients into four subgroups. We observed higher benefit in terms of DCR, median PFS and OS in the subgroup carrying exon 19, compared with exon 18 and 20 mutations.

Few data on the exon 19 insertions seem to confirm the positive predictive role of these mutations [11]: as reported by $\mathrm{He}$ et al. mutated cells are sensitive to TKIs both in vitro and in vivo, thus constituting a new family of sensitizing mutations. [33] Patients harboring exon 18 mutations (E709X and G719X) achieved shorter median

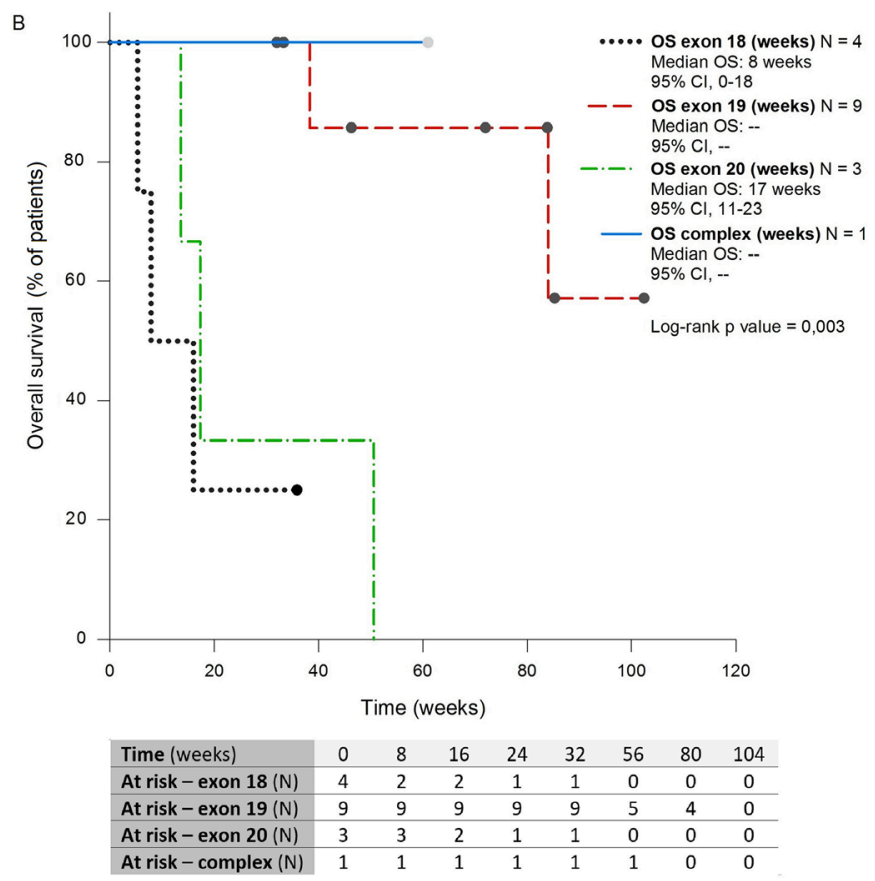

Figure 3: Kaplan-Meier curves showing PFS (A) and OS (B) of patients with NSCLC harboring rare and complex EGFR mutations, receiving EGFR TKIs front-line, of four subgrups defined according to mutation type. PFS: Progression-free Survival; OS: Overall Survival; CI: Confidence Interval 
PFS and OS with only one case of PR to gefitinib. These findings agree with published results, reporting low, although heterogeneous, response rates (0\% to 37\%) and dismal prognosis (median PFS from 1.3 to 6.3 months). $[19,28,41]$ A post hoc analysis of NEJ002 study showed lower efficacy of gefitinib than chemotherapy in people with G719X and L861Q mutations, without significant differences between the two mutations [18]. In contrast, in subjects with G719X mutation (alone or in combination) treated with afatinib both RR and median PFS (77.8\% and 13.8 months, respectively) are greater than those receiving chemotherapy [9], thus suggesting second-generation TKIs as a possible option in this mutations class [21]. Survival data of subgroup 3 were significantly lower compared to subgroup 2 but not subgroup 1, probably due to the limited sample size. Our study confirms the primary TKIs resistance in patients carrying exon 20 alterations, with all $(N=3)$ cases developing PD as best response. All literature data about exon 20 mutations show a very low RR (about $8 \%$ ) and poor median PFS (about 2.5 months) with first two generation TKIs [9, 41]. Few data instead exist on isolated point mutations, in particular the S768X, which might confer an intermediate sensitivity to targeted therapy [19]; in our study, however, only one patient had the above mutation (S768R) and did not achieve any response to therapy.

Unlike the other subgroups, the most appropriate treatment in these patients might be chemotherapy, as confirmed by disease stabilization achieved in our case series. The only patient with complex mutation treated with an irreversible TKI showed a good response and survival. Data about this particular kind of subpopulation are lacking, with an isolated study showing poor RR, however without translating into a survival reduction.[43]

Molecular cancer heterogeneity is decisive, since treatment effectiveness appears to depend on the specific mix of carried mutations: RR and PFS seem better [44] in presence of a common mutation, and increase further, in case of co-presence of the two commonest mutations. Targeted drugs appear to be the best therapeutic option for these patients.

Despite an overall incidence of any grade AE of $78 \%$ with TKIs, a single serious AE (G3 diarrhea) was recorded. Even though no significantly different incidence of AE was shown among the three drugs, we confirmed their peculiar safety profile and showed more frequent dose reduction or temporary treatment interruption with afatinib; $[45,46]$ anyway there was no case of definitive therapy discontinuation for AEs. Overall, our data confirmed TKIs as a well tolerated treatment, with a peculiar toxicity profile manageable with supportive care or dose reductions.[47] MassARRAY analysis did not detect additional alterations in driver genes in this small subgroup of cases. It can be assumed that the EGFRm are important drivers for tumor growth and that, in subjects non-responsive to TKIs therapy, primary resistance is due to the specific EGFR alterations, rather than being accounted for by other concomitant mechanisms. These hypotheses should, however, be confirmed in larger series. The main limitations of this study consist in the small number of patients involved, due to the rarity of the condition, and the retrospective nature of the study.

Even though a prospective multicenter study should be performed in order to propose a treatment algorithm in such uncommon or complex EGFRm, clinical cases or series report acquire their own relevance in the context of clinical practice.

\section{MATERIALS AND METHODS}

\section{Patient population}

Data from patients with histological diagnosis of non-squamous lung cancer have been collected retrospectively from January 2010 to December 2015. Histological samples were obtained with surgical excision, surgical biopsy, trans-bronchial or computerized tomography (CT) scan guided biopsy of primary tumor, surgery or biopsy of metastatic sites. All subjects with at least one rare and/or complex EGFRm were included. A brain-thorax-abdomen CT scan was performed before starting systemic treatment for advanced/metastatic disease with successive radiological assessment every 2-3 months, according to clinical practice. Before study inclusion, all patients signed the informed consent form, according to privacy protective rules for recording clinical data for research and study purposes. The following clinical data were collected: gender, age, smoking status, histology, disease stage at diagnosis according to 7 th edition Classification of Malignant Tumors (TNM) of NSCLC [25], metastatic sites at diagnosis or at disease recurrence. A subject was classified as former-smoker if smoking habits interrupted by at least one year.

\section{Mutational analysis}

Mutational analysis of exon 18-21 of EGFR gene was performed at the time of histological diagnosis and in any case before the start of first line systemic treatment, through Sanger sequencing, PCR-based methods, or pyrosequencing. In the subgroup of patients with complex or rare mutations not responsive to first or second generation TKIs, the mutational status of genes different from EGFR has been investigated by massARRAY (Sequenom) analysis; investigated genes included kras, braf, nras, pi3kca, alk, erbb2, ddr2, mapk1 and ret.

\section{Treatment}

First line systemic treatment of patients with advanced/metastatic disease was administered according to national and international guidelines. In particular, a 
first (erlotinib or gefitinib) or second (afatinib) generation TKI was prescribed in cases with EGFRm with unknown predictive value. Patients harboring EGFRm more frequently associated with resistance to targeted therapy (for example, exon 20 insertions) have been treated with standard chemotherapy (platinum-based doublet plus pemetrexed or gemcitabine or paclitaxel; platinum-based triplet plus gemcitabine and bevacizumab) or were included in clinical trials, when available. TKIs were administered per os daily with initial dose of $150 \mathrm{mg}, 250 \mathrm{mg}$ and 40 mg for erlotinib, gefitinib and afatinib respectively, until disease progression or death, unacceptable toxicity or patient refusal. Drug choice was at the physician discretion.

\section{Efficacy and safety assessment}

Best radiological response by CT imaging was assessed in all patients who received a systemic treatment for advanced/metastatic disease, and classified in CR, PR, $\mathrm{SD}$ and PD according to Response Evaluation Criteria In Solid Tumors (RECIST) 1.1 criteria [26]. Best response rate (RR) was calculated as the proportion of subjects with $\mathrm{CR}$ and PR to treatment, while disease control rate (DCR) was calculated as the proportion of patients with CR, PR and SD.

Progression free survival (PFS) to first line therapy was measured as the time between diagnosis of advanced disease and first evidence of progression during or after first line therapy, or death for any cause; overall survival (OS) was measured as the time elapsed from diagnosis of advanced/metastatic disease and death for any cause. Best radiological response and survival data were reported for the intention-to-treat population and for the subgroup of patients receiving a first line TKI.

We also assessed TKIs best response and survival in four patient subgroups, according to the mutation type: subgroup 1 (rare mutations in exon 18); subgroup 2 (rare mutations in exon 19); subgroup 3 (rare mutations in exon 20); subgroup 4 (complex mutations).

All AE were registered and graded through Common Terminology Criteria for Adverse Events (CTCAE) version 4.0. [27] in patients treated with first line TKIs.

\section{Statistical analysis}

RR and DCR binomial proportion confidence interval was calculated with Clopper-Pearson exact test. Different response rates among patient subgroups were analyzed with Fisher exact test. PFS and OS curves were designed with Kaplan-Meier method. PFS was analyzed according to these covariates: age ( $<70$ versus $\geq 70$ years old), stage (IIIb versus IV), ECOG PS (0 versus $\geq 1$ ), best response to first line therapy (PR/SD versus $\mathrm{PD}$ ), number of metastatic sites ( $<3$ versus $\geq 3$ ), smoking status (exposed versus not exposed), TKI generation (first versus second), histological subtype (mucinous/enteric versus not mucinous/enteric). The same variables were considered in OS analysis, with the addition of data about any subsequent treatment lines (yes versus no). Logrank test and Cox proportional risk model were used to estimate the impact of such variables on PFS and on OS. Differences of adverse events among different TKIs were analyzed with exact Fisher test. Statistical analyses were performed through SigmaPlot software.

\section{Abbreviations}

AEs: Adverse Events: CR: Complete Response: CTCAE: Common Toxicity Criteria for Adverse Events: DCR: Disease Control Rate: ECOG: Eastern Cooperative Oncology Group: EGFR: Epidermal Growth Factor Receptor: EGFRm: EGFR mutations: ELREA: E746-A750 deletion on exon 19: G: Grade: NSCLC: Non-Small Cell Lung Cancer: OS: Overall Survival: PD: Progressive Disease: PFS: Progression Free Survival: PR: Partial Response: PS: Performance Status: RECIST: Response Evaluation Criteria In Solid Tumours: RR: Response Rate: SD: Stable Disease: TKIs: Tyrosine Kinase Inhibitors

\section{Authors' contributions}

Dr. S. Frega and Dr. M. Lorenzi contributed to: database collection, data analyses, literature data collection, some manuscript sections writing.

Dr. M. Fassan, Dr. Stefano Indraccolo, Prof. F. Calabrese and Dr. F. Lunardi contributed to: pathological assessment and molecular analyses.

Dr. A. Favaretto, L. Bonanno, V. Polo, G. Zago, I. Attili, A. Pavan contributed to: case series collection and patients' medical management.

Prof. M. Rugge, V. Guarneri and P.F. Conte contributed to: final work supervision and manuscript critical comments.

Dr. G. Pasello contributed to: study design, case series collection and patients' medical management, data analyses, manuscript writing and final approval.

\section{CONFLICTS OF INTEREST}

The authors had no conflicts of interest to declare.

\section{FUNDING}

This research did not receive any specific grant from funding agencies in the public, commercial, or not-forprofit sectors.

\section{REFERENCES}

1. Lynch T, Bell D, Sordella R, Gurubhagavatula S, Okimoto R, Brannigan B, Harris P, Haserlat S, Supko J, Haluska F, Louis D, Christiani D, Settleman J, et al. Activating mutations in the epidermal growth factor receptor underlying responsiveness of non-small-cell lung 
cancer to gefitinib. The New England journal of medicine. 2004; 350:2129-2139.

2. Midha A, Dearden S, McCormack R. EGFR mutation incidence in non-small-cell lung cancer of adenocarcinoma histology: a systematic review and global map by ethnicity (mutMapII). American journal of cancer research. 2015; 5:2892-2911.

3. Yu J, Yu S, Wang S, Bai H, Zhao J, An T, Duan J, Wang J. Clinical outcomes of EGFR-TKI treatment and genetic heterogeneity in lung adenocarcinoma patients with EGFR mutations on exons 19 and 21. Chinese Journal of Cancer. 2016; 35:30-30.

4. Mok T, Wu Y, Thongprasert S, Yang C, Chu D, Saijo N, Sunpaweravong $\mathrm{P}$, Han B, Margono B, Ichinose $\mathrm{Y}$, Nishiwaki Y, Ohe Y, Yang J, et al. Gefitinib or carboplatinpaclitaxel in pulmonary adenocarcinoma. The New England journal of medicine. 2009; 361:947-957.

5. Rosell R, Carcereny E, Gervais R, Vergnenegre A, Massuti B, Felip E, Palmero R, Garcia-Gomez R, Pallares C, Sanchez JM, Porta R, Cobo M, Garrido P, et al. Erlotinib versus standard chemotherapy as first-line treatment for European patients with advanced EGFR mutation-positive non-small-cell lung cancer (EURTAC): a multicentre, open-label, randomised phase 3 trial. The Lancet Oncology. 2012; 13:239-246.

6. Sequist L, Yang J, Yamamoto N, O’Byrne K, Hirsh V, Mok T, Geater S, Orlov S, Tsai C, Boyer M, Su W, Bennouna J, Kato T, et al. Phase III study of afatinib or cisplatin plus pemetrexed in patients with metastatic lung adenocarcinoma with EGFR mutations. Journal of clinical oncology. 2013; 31:3327-3334.

7. Wu Y, Zhou C, Hu C, Feng J, Lu S, Huang Y, Li W, Hou M, Shi J, Lee K, Xu C, Massey D, Kim M, et al. Afatinib versus cisplatin plus gemcitabine for first-line treatment of Asian patients with advanced non-small-cell lung cancer harbouring EGFR mutations (LUX-Lung 6): an open-label, randomised phase 3 trial. Lancet oncology. 2014; 15:213-222.

8. Fukuoka M, Wu Y, Thongprasert S, Sunpaweravong P, Leong S, Sriuranpong V, Chao T, Nakagawa K, Chu D, Saijo N, Duffield E, Rukazenkov Y, Speake G, et al. Biomarker analyses and final overall survival results from a phase III, randomized, open-label, first-line study of gefitinib versus carboplatin/paclitaxel in clinically selected patients with advanced non-small-cell lung cancer in Asia (IPASS). Journal of clinical oncology. 2011; 29:2866-2874.

9. Yang JC, Wu Y, Schuler M, Sebastian M, Popat S, Yamamoto N, Zhou C, Hu C, O'Byrne K, Feng J, Lu S, Huang Y, Geater SL, et al. Afatinib versus cisplatinbased chemotherapy for EGFR mutation-positive lung adenocarcinoma (LUX-Lung 3 and LUX-Lung 6): analysis of overall survival data from two randomised, phase 3 trials. The Lancet Oncology. 2015; 16:141-151.

10. Zhang Y, Sheng J, Kang S, Fang W, Yan Y, Hu Z, Hong S, Wu X, Qin T, Liang W, Zhang L. Patients with exon 19 deletion were associated with longer progression-free survival compared to those with L858R mutation after firstline EGFR-TKIs for advanced non-small cell lung cancer: a meta-analysis. PLoS One. 2014; 9: e107161-e107161.

11. D'Arcangelo M, D'Incecco A, Cappuzzo F. Rare mutations in non-small-cell lung cancer. Future oncology. 2013; 9:699-711.

12. Massarelli E, Johnson F, Erickson H, Wistuba I, Papadimitrakopoulou V. Uncommon epidermal growth factor receptor mutations in non-small cell lung cancer and their mechanisms of EGFR tyrosine kinase inhibitors sensitivity and resistance. Lung Cancer. 2013; 80:235-241.

13. Chen Z, Feng J, Saldivar J, Gu D, Bockholt A, Sommer SS. EGFR somatic doublets in lung cancer are frequent and generally arise from a pair of driver mutations uncommonly seen as singlet mutations: one-third of doublets occur at five pairs of amino acids. Oncogene. 2008; 27:4336-4343.

14. Hata A, Yoshioka H, Fujita S, Kunimasa K, Kaji R, Imai Y, Tomii K, Iwasaku M, Nishiyama A, Ishida T, Katakami N. Complex Mutations in the Epidermal Growth Factor Receptor Gene in Non-small Cell Lung Cancer. Journal of Thoracic Oncology. 2010; 5:1524-1528.

15. Keam B, Kim D, Park J, Lee J, Kim T, Lee S, Chung D, Heo D. Rare and complex mutations of epidermal growth factor receptor, and efficacy of tyrosine kinase inhibitor in patients with non-small cell lung cancer. International Journal of Clinical Oncology. 2014; 19:594-600.

16. Peng L, Song Z, Jiao S. Efficacy analysis of tyrosine kinase inhibitors on rare non-small cell lung cancer patients harboring complex EGFR mutations. Scientific Reports. 2014; 4:6104-6104.

17. Kim E, Cho E, Park H, Hong J, Lim S, Youn J, Hwang S, Chang Y. Compound EGFR mutation is frequently detected with co-mutations of actionable genes and associated with poor clinical outcome in lung adenocarcinoma. Cancer biology \& therapy. 2016; 17:237-245.

18. Watanabe S, Minegishi Y, Yoshizawa H, Maemondo M, Inoue A, Sugawara S, Isobe $\mathrm{H}$, Harada $\mathrm{M}$, Ishii $\mathrm{Y}$, Gemma A, Hagiwara K, Kobayashi K. Effectiveness of gefitinib against non-small-cell lung cancer with the uncommon EGFR mutations G719X and L861Q. Journal of thoracic oncology. 2014; 9:189-194.

19. Chiu C, Yang C, Shih J, Huang M, Su W, Lai R, Wang C, Hsiao S, Lin Y, Ho C, Hsia T, Wu M, Lai C, et al. Epidermal Growth Factor Receptor Tyrosine Kinase Inhibitor Treatment Response in Advanced Lung Adenocarcinomas with G719X/L861Q/S768I Mutations. Journal of thoracic oncology. 2015; 10:793-799.

20. Yang JC, Sequist L, Geater S, Tsai C, Mok TSK, Schuler M, Yamamoto N, Yu C, Ou S, Zhou C, Massey D, Zazulina V, $\mathrm{Wu}$ Y. Clinical activity of afatinib in patients with advanced non-small-cell lung cancer harbouring uncommon EGFR mutations: a combined post-hoc analysis of LUX-Lung 2, LUX-Lung 3, and LUX-Lung 6. Lancet oncology. 2015; 16:830-838.

21. Kobayashi Y, Togashi Y, Yatabe Y, Mizuuchi H, Jangchul P, Kondo C, Shimoji M, Sato K, Suda K, Tomizawa K, 
Takemoto T, Hida T, Nishio K, et al. EGFR Exon 18 Mutations in Lung Cancer: Molecular Predictors of Augmented Sensitivity to Afatinib or Neratinib as Compared with First- or Third-Generation TKIs. Clinical cancer research. 2015; 21:5305-5313.

22. Yasuda H, Kobayashi S, Costa D. EGFR exon 20 insertion mutations in non-small-cell lung cancer: preclinical data and clinical implications. Lancet oncology. 2012; 13:e23-e31.

23. Stewart E, Tan S, Liu G, Tsao M. Known and putative mechanisms of resistance to EGFR targeted therapies in NSCLC patients with EGFR mutations-a review. Translational Lung Cancer Research. 2015; 4:67-81.

24. Yun C, Mengwasser K, Toms A, Woo M, Greulich H, Wong K, Meyerson M, Eck M. The T790M mutation in EGFR kinase causes drug resistance by increasing the affinity for ATP. Proceedings of the National Academy of Sciences of the United States of America. 2008; 105:2070-2075.

25. Mirsadraee S, Oswal D, Alizadeh Y, Caulo A, van Beek E. The 7th lung cancer TNM classification and staging system: Review of the changes and implications. World Journal of Radiology. 2012; 4:128-134.

26. Eisenhauer EA, Therasse P, Bogaerts J, Schwartz LH, Sargent D, Ford R, Dancey J, Arbuck S, Gwyther S, Mooney M, Rubinstein L, Shankar L, Dodd L, et al. New response evaluation criteria in solid tumours: revised RECIST guideline (version 1.1). European journal of cancer. 2009; 45:228-247.

27. Common Terminology Criteria for Adverse Events (CTCAE) Version 4.0 Published: May 28, 2009 (v4.03: June 14, 2010) U.S.DEPARTMENT OF HEALTH AND HUMAN SERVICES National Institutes of Health National Cancer Institute.

28. Beau Faller M, Prim N, Ruppert A, Nanni Metéllus I, Lacave R, Lacroix L, Escande F, Lizard S, Pretet J, Rouquette I, de Crémoux P, Solassol J, de Fraipont F, et al. Rare EGFR exon 18 and exon 20 mutations in nonsmall-cell lung cancer on 10117 patients: a multicentre observational study by the French ERMETIC-IFCT network. Annals of oncology. 2014; 25:126-131.

29. Stone E, Allen HA, Saghaie T, Abbott A, Daniel R, Mead RS, Kohonen Corish M, Plit M, Morgan L. High proportion of rare and compound epidermal growth factor receptor mutations in an Australian population of nonsquamous non-small-cell lung cancer. Internal Medicine Journal. 2014; 44:1188-1192.

30. Chen Z, Feng J, Buzin C, Sommer S. Epidemiology of doublet/multiplet mutations in lung cancers: evidence that a subset arises by chronocoordinate events. PLoS One. 2008; 3: e3714-e3714.

31. Woo H, Ahn H, Lee H, Park I, Kim Y, Hong J, Sym S, Park J, Lee J, Shin D, Cho E. Epidermal growth factor receptor (EGFR) exon 20 mutations in non-small-cell lung cancer and resistance to EGFR-tyrosine kinase inhibitors. Investigational new drugs. 2014; 32:1311-1315.
32. Arcila M, Nafa K, Chaft J, Rekhtman N, Lau C, Reva B, Zakowski M, Kris M, Ladanyi M. EGFR exon 20 insertion mutations in lung adenocarcinomas: prevalence, molecular heterogeneity, and clinicopathologic characteristics. Molecular cancer therapeutics. 2013; 12:220-229.

33. He M, Capelletti M, Nafa K, Yun C, Arcila M, Miller V, Ginsberg M, Zhao B, Kris M, Eck M, Jänne P, Ladanyi M, Oxnard G. EGFR exon 19 insertions: a new family of sensitizing EGFR mutations in lung adenocarcinoma. Clinical cancer research. 2012; 18:1790-1797.

34. Frega S, Conte P, Fassan M, Polo V, Pasello G. A Triple Rare E709K and L833V/H835L EGFR Mutation Responsive to an Irreversible Pan-HER Inhibitor: A Case Report of Lung Adenocarcinoma Treated with Afatinib. Journal of thoracic oncology. 2016; 11: e63-e64.

35. Yang T, Tsai C, Chen K, Hsu K, Lee H, Chang G. Good response to gefitinib in a lung adenocarcinoma harboring a heterozygous complex mutation of L833V and H835L in epidermal growth factor receptor gene. Journal of clinical oncology. 2011; 29: e468-e469.

36. Villa C, Cagle P, Johnson M, Patel J, Yeldandi A, Raj R, DeCamp M, Raparia K. Correlation of EGFR mutation status with predominant histologic subtype of adenocarcinoma according to the new lung adenocarcinoma classification of the International Association for the Study of Lung Cancer/American Thoracic Society/European Respiratory Society. Archives of Pathology \& Laboratory Medicine. 2014; 138:1353-1357.

37. Russell PA, Barnett SA, Walkiewicz M, Wainer Z, Conron M, Wright GM, Gooi J, Knight S, Wynne R, Liew D, John T. Correlation of Mutation Status and Survival with Predominant Histologic Subtype According to the New IASLC/ATS/ERS Lung Adenocarcinoma Classification in Stage III (N2) Patients. Journal of Thoracic Oncology. 2013; 8:461-468.

38. D'Angelo S, Pietanza MC, Johnson M, Riely G, Miller V, Sima C, Zakowski M, Rusch V, Ladanyi M, Kris M. Incidence of EGFR exon 19 deletions and L858R in tumor specimens from men and cigarette smokers with lung adenocarcinomas. Journal of clinical oncology. 2011; 29:2066-2070.

39. Lohinai Z, Hoda M, Fabian K, Ostoros G, Raso E, Barbai T, Timar J, Kovalszky I, Cserepes M, Rozsas A, Laszlo V, Grusch M, Berger W, et al. Distinct Epidemiology and Clinical Consequence of Classic Versus Rare EGFR Mutations in Lung Adenocarcinoma. Journal of thoracic oncology. 2015; 10:738-746.

40. Pallis AG, Voutsina A, Kalikaki A, Souglakos J, Briasoulis E, Murray S, Koutsopoulos A, Tripaki M, Stathopoulos E, Mavroudis D, Georgoulias V. 'Classical' but not 'other' mutations of EGFR kinase domain are associated with clinical outcome in gefitinib-treated patients with non-small cell lung cancer. British journal of cancer. 2007; 97:1560-1566. 
41. Baek J, Sun J, Min Y, Cho E, Cho B, Kim J, Ahn M, Park K. Efficacy of EGFR tyrosine kinase inhibitors in patients with EGFR-mutated non-small cell lung cancer except both exon 19 deletion and exon 21 L858R: a retrospective analysis in Korea. Lung Cancer. 2015; 87:148-154.

42. Kobayashi Y, Mitsudomi T. Not all EGFR mutations in lung cancer are created equal: Perspectives for individualized treatment strategy. Cancer science. 2016; 107:1179-1186.

43. Wei Z, An T, Wang Z, Chen K, Bai H, Zhu G, Duan J, Wu M, Yang L, Zhuo M, Wang Y, Liu X, Wang J. Patients harboring epidermal growth factor receptor (EGFR) double mutations had a lower objective response rate than those with a single mutation in non-small cell lung cancer when treated with EGFR-tyrosine kinase inhibitors. Thoracic Cancer. 2014; 5:126-132.

44. Wu S, Chang Y, Hsu Y, Wu J, Yang C, Yu C, Tsai M, Shih J, Yang P. Good response to gefitinib in lung adenocarcinoma of complex epidermal growth factor receptor (EGFR) mutations with the classical mutation pattern. The oncologist. 2008; 13:1276-1284.
45. Park K, Tan E, O’Byrne K, Zhang L, Boyer M, Mok T, Hirsh V, Yang JC, Lee KH, Lu S, Shi Y, Kim S, Laskin J, et al. Afatinib versus gefitinib as first-line treatment of patients with EGFR mutation-positive non-small-cell lung cancer (LUX-Lung 7): a phase 2B, open-label, randomised controlled trial. The Lancet Oncology. 2016; 17:577-589.

46. Haspinger E, Agustoni F, Torri V, Gelsomino F, Platania M, Zilembo N, Gallucci R, Garassino M, Cinquini M. Is there evidence for different effects among EGFR-TKIs? Systematic review and meta-analysis of EGFR tyrosine kinase inhibitors (TKIs) versus chemotherapy as first-line treatment for patients harboring EGFR mutations. Critical reviews in oncology/hematology. 2015; 94:213-227.

47. Normando SRC, Cruz F, Del Giglio A. Cumulative metaanalysis of epidermal growth factor receptor-tyrosine kinase inhibitors as first-line therapy in metastatic non-small-cell lung cancer. Anti-Cancer Drugs. 2015; 26:995-1003. 